\title{
Analysis of Adenovirus -Vectored Foot-and-Mouth Disease Virus Transgene Expression in Bovine Kidney Cells by Confocal, Electron, and Immuno- electron Microscopy
}

\author{
T.G. Burrage*, M.J. Grubman**, D.A. Brake***, J.N. Neilan***, E.J. Kramer*** D. E. \\ Brough****and B. G. Harper*** \\ *Viral, Cellular and Molecular Imaging, Science and Technology Directorate, Department of \\ Homeland Security, Plum Island Animal Disease Center, Greenport, NY 11944 \\ **Agricultural Research Service, United States Department of Agriculture, Plum Island Animal \\ Disease Center, Greenport, NY 11944 \\ ***Targeted Advanced Development, Science and Technology Directorate, Department of \\ Homeland Security, Plum Island Animal Disease Center, Greenport, NY 11944. \\ ****GenVec Inc., 65 West Watkins Mill Rd., Gaithersburg, MD. 20878
}

Foot-and-mouth disease (FMD) is an easily transmitted viral disease of cattle, swine and wild cloven-hoofed animals. Infection of domestic animals with FMD virus (FMDV), a picornavirus, results in diminished productivity and severe economic consequences for exporting countries [1]. To overcome drawbacks posed by current, inactivated FMD vaccines, we developed a replication-deficient, human adenovirus serotype 5 (Ad5) viral vectored FMD vaccine (Ad5FMD) platform $[2,3]$. In this study, we examined the cellular and sub-cellular changes after infection of fetal bovine kidney cells with Ad5-FMD vaccine virus candidates for two different FMDV serotypes (Ad5-FMD1, Ad5-FMD2). Cells were infected with Ad5-FMD1, Ad5-FMD2 or control vector (Ad5-Null) and harvested 24 hours later. For confocal microscopy, we fixed cells with $-20^{\circ} \mathrm{C}$ methanol, for electron microscopy (EM) with $2.5 \%$ glutaraldehyde, and for immune-electron microscopy with $4 \%$ formaldehyde. Transgene expression at the cellular and ultrastructural level was detected using FMDV-specific monoclonal antibodies (Mabs) to FMDV structural proteins VP1 and VP2 combined with anti-mouse-antibodies and -Fab fragments labeled with Alexa 488 (Molecular Probes) and $0.8 \mathrm{~nm}$ gold (Nanoprobes), respectively. Cells infected with Ad5-Null vector showed no labeling (data not shown). Results following Ad5FMD1 infection showed two distinct distributions of cellular labeling that were dependent on the Mab used. Cells infected with Ad5-FMD1 displayed a fine-stippled, homogeneous distribution with anti-VP1 and small granules with the linear binding epitope anti-VP2 Mab (Fig. 1). In contrast, cells infected with Ad5-FMD2 showed small numbers of large and small intenselystaining granules with both anti-VP1 and anti-VP2 and small granules anti-VP2 . No crossreactivity was evident with anti-VP1 (Fig. 2). Apoptotic nuclear changes and abundance of autophagic (APV) multi-lamellar and empty (V) vesicles characterize cells infected with Ad5FMD1 (Fig. 3) but not those infected with Ad5-Null. In addition to the cytoplasmic changes, cells infected with Ad5-FMD2 had large and small crystalline arrays of non-membrane associated virus-like particles (VLPs) approximately $25+0.2 \mathrm{~nm}$ in diameter (Figs. 4 and 5). These empty particles were densely labeled with anti-VP1 and anti-VP2 and gold-enhanced nanogold but not with a control antibody (Fig. 6). The uniform diameter and immune-specific labeling strongly indicate that these structures are self-assembled, empty FMDV capsids. In summary, this study is the first demonstration of the cellular transgene expression of FMD VLPs. 
References

[1] M. J. Grubman and B. Baxt, Clin. Microbiol. Rev. 17 (2004) 465.

[2] M. J. Grubman et al., Future Virol. 5 (2010) 51.

[3] L. L. Rodriguez and M. J. Grubman Vaccine 27 (2009) 90.

[4] This research was supported by the Department of Homeland Security, Science and

Technology Directorate. The cells were kindly provided by Dr. J. Pacheco, PIADC, ARS, USDA.
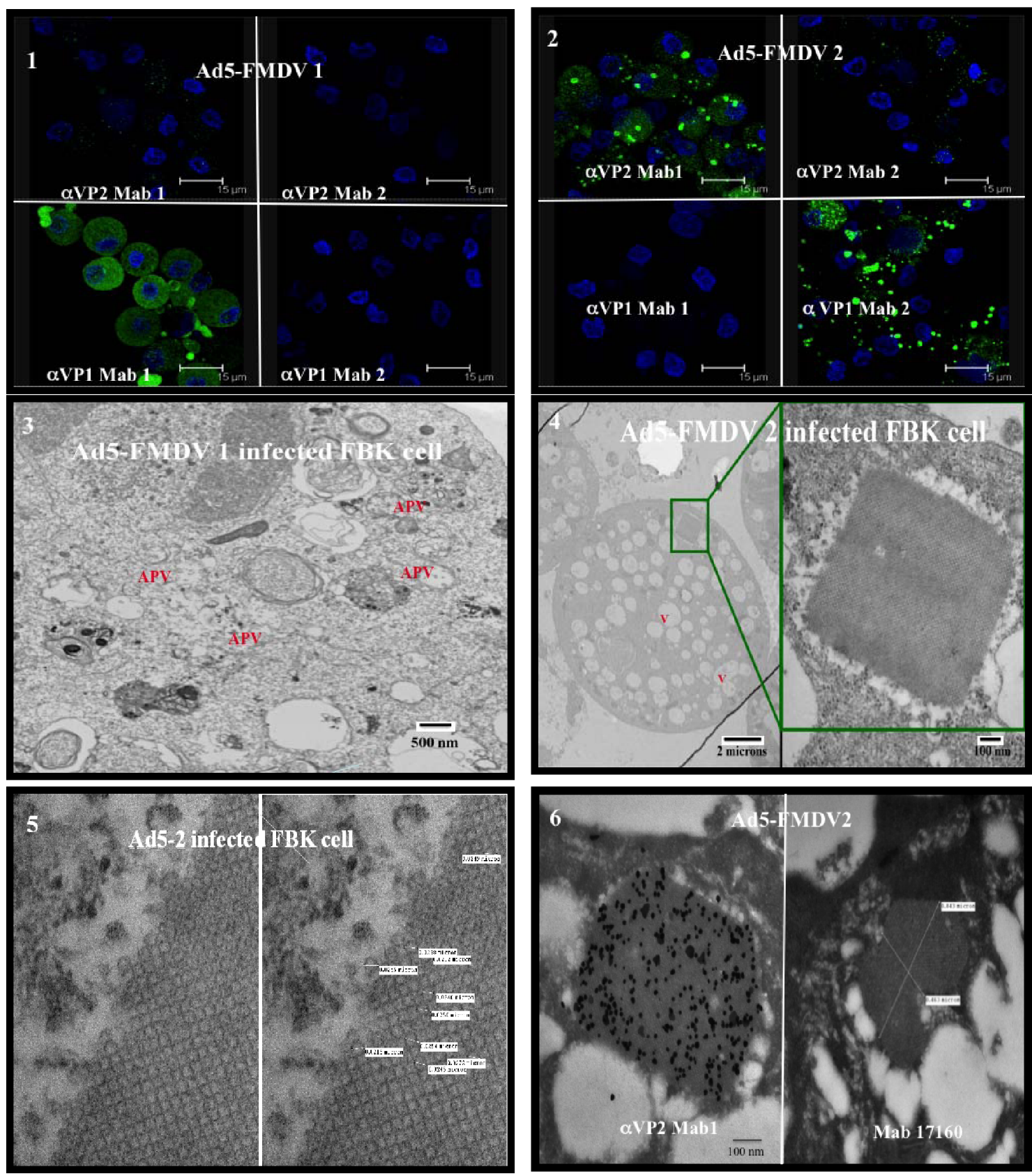